\title{
Microbiological Profile of Lower Respiratory Tract Infections in MICU in a Tertiary Care Hospital
}

\author{
Anil A. Gaikwad*, Payal Rahangdale, Jyoti A. Iravane (Bajaj), Shaikh Ambreen Fatema \\ Abdul Hafiz and Nashrah Khan
}

Department of Microbiology, Govt. Medical College, Aurangabad-431001, Maharashtra, India

*Corresponding author

\section{A B S T R A C T}

Keywords

Antibiotic

resistance patterns, LRTI

Article Info

Accepted:

10 January 2021

Available Online:

10 February 2021
Lower respiratory tract infections (LRTI's) are the most frequent infections among patients in intensive care units. The consequences of increased drug resistance are far reaching since bacterial infection of the lower respiratory tract is a major cause of death from infectious disease. This was a prospective study of clinically suspected cases of LRTI's over a period of 6 months from Jan 2019 to June 2019. Lower respiratory tract samples were inoculated on BA, CA, MAC agar and incubated overnight \& AST was performed after identification. 124 (88.5\%) of total 140 samples were positive for bacterial culture. $118(84.28 \%)$ were gram negative bacilli (GNB) and $6(4.2 \%)$ were gram positive cocci (GPC). Occurrence of LRTI was $71.4 \%$ with dominance of males and age group of 20-65 years. Klebsiella spp. (59.28\%) was the most common isolate followed by Pseudomonas aeruginosa (11.4\%), E. coli (7.1\%), Acinetobacter baumannii (6.4\%), Staphylococcus aureus (4\%). Susceptibility of GNB was highest towards Imipenem followed by Piperacillin-tazobactam. Gram positive organisms exhibited highest susceptibility towards Vancomycin and Linezolid. The resistance pattern of these pathogens can help to formulate effective antimicrobial policy. Therefore, an ultimate and detailed bacteriological diagnosis and susceptible testing is required to overcome global problem of antibiotic resistance.

\section{Introduction}

Lower respiratory tract infection is defined as an acute illness usually for a period of 13 weeks, presenting with symptoms of cough, expectoration, dyspnoea, wheeze \& chest pain/discomfort. Various predisposing factors which may lead to LRTI are smoking, alcohol, immunosuppressive conditions, Diabetes mellitus, COPD, Bronchial asthma etc. ${ }^{1}$

Acute lower respiratory tract (ALRI) infections are among the most common infectious diseases affecting humans worldwide causing significant morbidity and mortality for all age groups. It is liable for 
$4.4 \%$ of all hospital admissions and $6 \%$ of GP consultations. It accounts for 3 to $5 \%$ of deaths in adults globally, about 4.2 million ALRI deaths are estimated to occur among all age Groups. The problem is much greater in developing countries where pneumonia is the most common cause of hospital attendance in adults. ${ }^{4}$

Age, gender and season can affect the occurrence of LRTI's. Pneumonia in adults occurs in $4 \%$ of Indians with male to female ratio of 1.56:1.14 and an annual incidence rate of (1.12-3.16 per 1000 people), which is increased as age advances. ${ }^{2}$

The aetiological agents of LRTIs vary from area to area, so the susceptibility profile will also differ between geographical locations. ${ }^{6}$

The dramaticrise in the antimicrobial resistance among the respiratory pathogens, presumably due to the prophylactic administration of antibacterial therapy even before the availability of the culture reports, is a matter of potential concernworldwide. ${ }^{7}$

This study has reviewed our current understanding on lower respiratory tract infections and it has emphasized the changing trends in their occurrence and therefore the antimicrobial susceptibility pattern of the respiratory pathogens which were isolated during a government hospital of western India, thus enabling the clinicians to appropriately formulate and endorse a competent and rational antibacterial policy, to further curb the incidence of the disease. ${ }^{8}$

\section{Materials and Methods}

The Prospective study was conducted in the Department of Microbiology in Government Medical College and Hospital during Jan 2019 to June 2019. A total of 140 patients admitted in Medicine Intensive Care Unit (MICU), who were provisionally diagnosed as Lower
Respiratory Tract Infection were enrolled in the study. Lower Respiratory Tract samples (Endotracheal aspirate) were collected \& transported immediately to Microbiology Laboratory and processed further.

The samples were inoculated onto Blood Agar (BA), Chocolate Agar (CA) \& MacConkey Agar (MAC) and incubated at $37^{\circ} \mathrm{C}$ for 24hours. After incubation, identification of bacterium from positive cultures was done with standard microbiological techniques which include Gram staining, motility testing by hanging drop preparation and various biochemical reactions such as Catalase, Coagulase, Indole, Methylred, VogesProskauer, Citrate, Urease and Oxidasetest etc.

The bacterial isolates were put up for susceptibility testing by standard Kirby Bauer disc diffusion methods on Muller Hinton Agar. The susceptibility patterns of the bacterial pathogens were determined following the panel of antimicrobial agents as recommended by Clinical Laboratory Standard Institute (CLSI) guidelines, 2019.

Depending on the isolate, antibiotic discs were applied and Zone diameter was measured in millimetres and interpreted as per CLSI guidelines. The entire testing was done under strict quality control and American Type Culture Collection (ATCC) strains were used as control strains.

\section{Results and Discussion}

A total of 140 samples were processed based on the standard microbiological methods. The results of the study revealed that out of the 140 samples tested, significant pathogens were isolated from $124(88.57 \%)$ samples and 16 (11.4\%) showed no growth (Graph 1). Of these $100(71.4 \%)$ samples were of males and $40(28.5 \%)$ samples of female's (Graph 2). The highest isolation rates were observed in the 
age group of 20-40 years followed by $40-60$ years of age group (Table 1).

Out of 140 cases of LRTI's, maximum number of cases were from Organophosphorus poisoning (OPP) with respiratory failure $(\mathrm{n}=$ 77), Pneumonia ( $\mathrm{n}=20)$, Pneumothorax (n =17), TB (n =10), Chronic Obstructive Pulmonary Disease (COPD) (n=9), GBS with respiratory failure $(\mathrm{n}=3)$ in which Klebsiella pneumoniae cause the highest no. of cases of LRTI's followed by Pseudomonas aeruginosa, E.coli, Acinetobacter baumannii and Staphylococcus aureus (Table 2).

Among the Culture positive isolates $118(84.2 \%)$, the predominant pathogen isolated was Klebsiella pneumoniae (59.28\%), followed by Pseudomonas aeruginosa (11.4\%), Escherichia coli (7.1\%), Acinetobacter baumannii (6.4\%) and Staphylococcus aureus (4.2\%) respectively (Table 3).

Out of the 140 samples tested, 124 showed significant growth in which, 18 samples $(14.5 \%)$ showed Polymicrobial infection (mostly by Klebsiella pneumoniae and Pseudomonas aeruginosa) and 106 samples $(85.4 \%)$ showed Monomicrobial infection (Table 4).

Gram positive isolates were $100 \%$ resistance to Penicillin $\mathrm{G}$ followed by Ciprofloxacin (83.3\%), Trimethoprim/ Sulfamethoxazole (66.7\%) (Table 5).

Most of the gram-negative bacterial isolates showed resistance to commonly used Cephalosporins. Klebsiella pneumoniae showed resistance to most of the drugs like Cefotaxime (100\%), Cefuroxime (99.4\%), Ampicillin (97.4\%), Amikacin (81.3\%), Ciprofloxacin (92.9\%), Gentamicin (71.4\%), Meropenem (81.8\%), Trimethoprim/
Sulfamethoxazole (86.5\%), Piperacillin/ Tazobactam $(87.1 \%)$.

Pseudomonas aeruginosa showed relatively more resistance to Cephalosporins, Ciprofloxacin (45.5\%), Ceftazidime (42.4\%), Meropenem (37.5\%), Amikacin (46.9\%), Gentamycin 936.4\%), Tobramycin (52.9\%), Piperacillin/Tazobactam (33.3\%).

E. coli showed resistance to most of the Cephalosporins, Fluoroquinolones and Meropenem (60\%), Piperacillin/Tazobactam (60\%), Amikacin (60\%), Gentamycin (53\%), Trimethoprim/Sulfamethoxazole (73\%).

Acinetobacter baumannii showed resistance to most of the Cephalosporins followed by Ciprofloxacin (91\%), Amikacin, Gentamycin (87\%), Meropenem (77.3), Pipercillin/ Tazobactum (87\%) (Table 6).

Confirmed LRTI cases were associated with either single risk factor or multiple comorbidities i.e. more than one risk factor. Out of which Multiple comorbidities (28\%) followed by Hypertension (13\%), Diabetes (17\%), Smoking (19\%) and Alcohol (10\%), Kidney disease (9\%).(Graph 3)

The present study provides an insight on the prevalence and antibiogram of the respiratory pathogens which were isolated from cases of Lower Respiratory Tract Infection (LRTI) admitted in MICU in Government Medical College, Aurangabad.

Lower Respiratory Tract samples (Endotracheal aspirate) culture positivity was found to be $88.5 \%$ (124outof140). The isolation rates reported by Ratna et al., ${ }^{7}$, Amutha et al., ${ }^{2}$ and Elumalai et al., ${ }^{6}$ were $39.77 \%, 51 \%$ and $65.14 \%$ respectively. The remaining 16 (11.4\%) Lower Respiratory Tract samples (Endotracheal aspirate) which yielded no growth in culture could be due to 
due to previous antibiotic therapy or viral aetiology.

Among the culture positive isolates, the predominant organism were Klebsiella pneumonia followed by Pseudomonas aeruginosa similar to a study done by Amarasinghe et al., ${ }^{14}$

Males were found to be more affected than females which was in concordance to a similar study by Dsouza et al., ${ }^{5}$ and Rana et al., 9 . This may be explained by male behaviour of more outdoor stay exposing them to air pollution than the female counterparts.

Moreover smoking habits are more pronounced in males that constitute one of the predisposing factors for the development of LRTIs. Smoking and pollution are responsible for decrease in mucociliary clearance and innate immunity. It leads to increased bacterial colonization that can give rise to increased airway inflammation and thus exacerbations. ${ }^{7}$

The age range in our study varies between 2060 years of age which was similar to Okesola et al., ${ }^{11}$ Kalgo et al., ${ }^{12}$ and Srivastav et al., ${ }^{13}$

Out of the culture positive samples, in 18 cases $(14.5 \%)$, more than two organisms were isolated. The isolation rates by Saha et al., ${ }^{1}$, Bajpai et al., ${ }^{10}$, Agmy et al., ${ }^{15}$ were $2.04 \%$, $24.24 \%, 12 \%$ respectively.

In the current study Gram positive organisms showed $100 \%$ susceptibility to Linezolid \& Vancomycin while possessing good susceptibility to Doxycycline, Trimethoprim/ Sulphamethoxazole, Tetracycline and followed by their reduced susceptibility to Penicillin, Ciprofloxacin, and Gentamycin. Out of $4 \%$ of the Staphylococcus aureus, four isolates were found to be Methicillin resistant (MRSA).
Vancomycin Susceptibility in Staphylococcus aureus was checked by using Vancomycin screen agar. ${ }^{23}$

For Gram positive bacterial infections, Aminoglycosides and Levofloxacin are widely recommended as first line drugs for empirical treatment reserving Vancomycin and Linezolid for resistant cases.

Similar findings were reported from some other investigators as well like Sarmah et al., Regha et al., ${ }^{4}$, Panda et al., ${ }^{19}$

There were also reports from India regarding increase prevalence of drug resistance among gram negative bacilli strains from LRTI ${ }^{18}$.

In our study also $K$. pneumoniae, E. coli, Acinetobacter baumannii strains have shown 95 to $100 \%$ resistance to Cephalosporins and Fluroquinolone's and $P$. aeruginosa was comparatively more susceptible to antibiotics.

$P$. aeruginosa had $60 \%$ susceptibility to Meropenem and Imipenem each, whereas all the 9 Acinetobacter baumannii were resistant to Carbapenems.

There were several antibiotic- resistance mechanisms working in $P$. aeruginosa and Acinetobacter spp. Moreover, high colonisation rates have been observed in the ICU setting, particularly in the respiratory tract. Thomas et al., ${ }^{17}$ conducted a detailed study on MDR Gram negative bacilli causing lower respiratory infections. They had K.pneumonia, Acinetobacter species as the commonest MDR isolates.

HighratesofresistancetoCephalosporinswasnoti cedinseveralstudiesTripathi et al., ${ }^{16}$ Nepal et al., ${ }^{20}$. Our observation about Cephalosporins match with their findings. This might be due to the extensive use of $3^{\text {rd }}$ generation Cephalosporins in hospitals. 
Table.1 Age wise distribution of cases of LRTI

\begin{tabular}{|c|c|c|c|}
\hline Age in years & Male & Female & Total \\
\hline $\mathbf{1 - 2 0}$ & 8 & 7 & $\mathbf{1 5}$ \\
\hline $\mathbf{2 0 - 4 0}$ & 46 & 20 & $\mathbf{6 6}$ \\
\hline $\mathbf{4 0 - 6 0}$ & 42 & 13 & $\mathbf{5 5}$ \\
\hline $\mathbf{6 0 - 8 0}$ & 2 & 1 & $\mathbf{3}$ \\
\hline $\mathbf{8 0 - 1 0 0}$ & $\mathbf{0}$ & $\mathbf{1}$ & $\mathbf{1}$ \\
\hline
\end{tabular}

$\mathrm{p}=0.248 \mathrm{NS}$ (since $\mathrm{p}>0.05$, there is no association exist between age and sex of the patients, it is not statistically significant)

Table.2 Correlation of cases of LRTI with microorganisms isolated in cases of LRTI's

\begin{tabular}{|c|c|c|c|c|c|c|}
\hline Diagnosis & $\begin{array}{c}\text { Number } \\
\text { of cases }\end{array}$ & $\begin{array}{c}\text { Klebsiella } \\
\text { pneumoniae }\end{array}$ & $\begin{array}{c}\text { Pseudomonas } \\
\text { aeruginosa }\end{array}$ & $\begin{array}{c}\text { Escherichia } \\
\text { coli }\end{array}$ & $\begin{array}{c}\text { Acinetobacter } \\
\text { baumannii }\end{array}$ & $\begin{array}{c}\text { Staph. } \\
\text { aureus }\end{array}$ \\
\hline $\begin{array}{c}\text { OPP With } \\
\text { Respiratory } \\
\text { Failure }\end{array}$ & 77 & 40 & 20 & 11 & 6 & $\mathbf{0}$ \\
\hline $\begin{array}{c}\text { Acute } \\
\text { Respiratory } \\
\text { Distress } \\
\text { Syndrome }\end{array}$ & 4 & 2 & 2 & 0 & 0 & $\mathbf{0}$ \\
\hline $\begin{array}{c}\text { Pneumonia } \\
\text { GBS with } \\
\text { Respiratory } \\
\text { Failure }\end{array}$ & 20 & 8 & 4 & 2 & 4 & $\mathbf{2}$ \\
\hline $\begin{array}{c}\text { COPD } \\
\text { Pneumothora }\end{array}$ & 17 & 1 & 2 & & & \\
\hline $\mathbf{x}$ & 7 & 7 & 2 & 0 & 0 & $\mathbf{0}$ \\
\hline Tuberculosis & $\mathbf{1 0}$ & $\mathbf{3}$ & $\mathbf{4}$ & $\mathbf{2}$ & $\mathbf{0}$ & $\mathbf{1}$ \\
\hline
\end{tabular}

$\mathrm{p}=0.43 \mathrm{NS}$ (Since $\mathrm{p}>0.05$, distribution of organisms with respect to diagnosis to diagnosis is natural and no significant difference exist i.e. a particular organism had no association with type of diagnosis so it is not statistically significant)

Table.3 Organism wise distribution of cases of LRTI's

\begin{tabular}{|c|c|c|}
\hline Name of Organism & $\begin{array}{c}\text { Total No. of } \\
\text { Isolation }\end{array}$ & Percentage \\
\hline Klebsiella pneumoniae & 83 & $\mathbf{5 9 . 2 8 \%}$ \\
\hline Pseudomonas aeruginosa & 16 & $\mathbf{1 1 . 4 \%}$ \\
\hline Escherichia coli & 10 & $\mathbf{7 . 1 \%}$ \\
\hline Acinetobacter baumannii & 9 & $\mathbf{6 . 4 \%}$ \\
\hline Staph.aureus & $\mathbf{6}$ & $\mathbf{4 \%}$ \\
\hline
\end{tabular}


Table.4 Type of Infection in cases of LRTI's

\begin{tabular}{|c|c|c|}
\hline Type of Infection & No. of isolation & $\%$ \\
\hline Polymicrobial infection & 18 & 14.5 \\
\hline Monomicrobial infection & $\mathbf{1 0 6}$ & $\mathbf{8 5 . 4}$ \\
\hline
\end{tabular}

Table.5 Gram positive cocci (Staphylococcus aureus) antibiogram pattern in cases of LRTI's

\begin{tabular}{|c|c|c|}
\hline Drugs & Resistance pattern (\%) & Sensitivity pattern (\%) \\
\hline Ciprofloxacin & 83.3 & $\mathbf{1 6 . 7}$ \\
\hline Clindamycin & 72.2 & $\mathbf{2 7 . 8}$ \\
\hline Doxycycline & 27.8 & $\mathbf{6 6 . 7}$ \\
\hline Erythromycin & 55.6 & $\mathbf{2 7 . 8}$ \\
\hline Cefoxitin & 83.3 & $\mathbf{1 6 . 7}$ \\
\hline Gentamicin & 72.2 & $\mathbf{2 7 . 8}$ \\
\hline Linezolid & 0 & $\mathbf{1 0 0}$ \\
\hline Penicillin G & 100 & $\mathbf{0}$ \\
\hline Trimethoprim/Sulfamethoxazole & 66.7 & $\mathbf{3 3 . 3}$ \\
\hline Tetracycline & 27.3 & $\mathbf{5 4 . 5}$ \\
\hline Vancomycin* & $\mathbf{0 . 0}$ & $\mathbf{1 0 0}$ \\
\hline
\end{tabular}

(*For Staphylococcus aureus, Vancomycin susceptibility was tested by Vancomycin screen agar)

Table.6 Gram negative bacilli antibiogram pattern in cases of LRTI's

\begin{tabular}{|c|c|c|c|c|c|c|c|c|}
\hline \multirow[t]{3}{*}{ Drugs } & \multicolumn{8}{|c|}{ Organism } \\
\hline & \multicolumn{2}{|c|}{$\begin{array}{c}\text { Pseudomonas } \\
\text { aeruginosa }\end{array}$} & \multicolumn{2}{|c|}{$\begin{array}{c}\text { Klebsiella } \\
\text { pneumoniae }\end{array}$} & \multicolumn{2}{|c|}{ Escherichia coli } & \multicolumn{2}{|c|}{$\begin{array}{c}\text { Acinetobacterbau } \\
\text { mannii }\end{array}$} \\
\hline & $\mathrm{R}(\%)$ & S (\%) & $\mathrm{R}(\%)$ & S (\%) & $\mathrm{R}(\%)$ & $\mathrm{S}(\%)$ & $\mathrm{R}(\%)$ & $\mathbf{S}(\%)$ \\
\hline Amikacin & 46.9 & 53.1 & 81.3 & 5.8 & 60 & 40 & 87 & 8.7 \\
\hline Ampicillin & 100 & 0 & 97.4 & 0.6 & 93.3 & 6.7 & - & - \\
\hline Ciprofloxacin & 45.5 & 48.5 & 92.9 & 3.2 & 80 & 6.7 & 91.3 & 8.7 \\
\hline Cefotaxime & - & - & 99.4 & 0.6 & 86.7 & 6.7 & 100 & $\mathbf{0}$ \\
\hline Cefepime & 42.4 & 57.6 & 95.5 & 1.3 & 86.7 & 13.3 & 95.7 & 4.3 \\
\hline Gentamycin & 36.4 & 63.6 & 74.8 & 23.9 & 53.3 & 46.7 & 87 & 8.7 \\
\hline Imipenem & 40 & 60 & 81.8 & 15.5 & 60 & 40 & 80 & 20 \\
\hline Levofloxacin & 41.2 & 58.8 & 89.3 & 3.9 & 62.5 & 37.5 & - & - \\
\hline Meropenem & 37.5 & 62.5 & 81.8 & 15.5 & 60 & 33.3 & 77.3 & 22.7 \\
\hline $\begin{array}{c}\text { Trimethoprim/ } \\
\text { Sulfamethoxazole }\end{array}$ & - & - & 86.5 & 12.3 & 73.3 & 26.7 & 82.6 & 17.4 \\
\hline Piperacillin/ Tazobactam & 33.3 & 60.6 & 87.1 & 9.7 & 60 & 26.7 & 87 & 13 \\
\hline Ceftazidime & 42.4 & 57.6 & - & - & - & - & 87 & 13 \\
\hline Ceftriaxone & 100 & 0 & 99.4 & 0.6 & - & - & 100 & $\mathbf{0}$ \\
\hline Minocycline & - & - & - & - & - & - & 59.1 & 40.9 \\
\hline Ampicillin/ Sulbactam & - & - & - & - & - & - & 95.7 & 4.3 \\
\hline Tetracycline & - & - & - & - & - & - & 68.2 & 31.8 \\
\hline Tobramycin & 52.9 & 47.1 & - & - & - & - & 72.7 & 27.3 \\
\hline Aztreonam & - & - & - & - & - & - & - & - \\
\hline Cefuroxime & - & - & 100 & - & 100 & - & - & - \\
\hline Colistin* & - & 100 & - & 100 & - & 100 & - & - \\
\hline
\end{tabular}

(* Colistin susceptibility was tested by Microbroth dilution, MBD) 
Graph.1 Isolation distribution in cases of LRTI

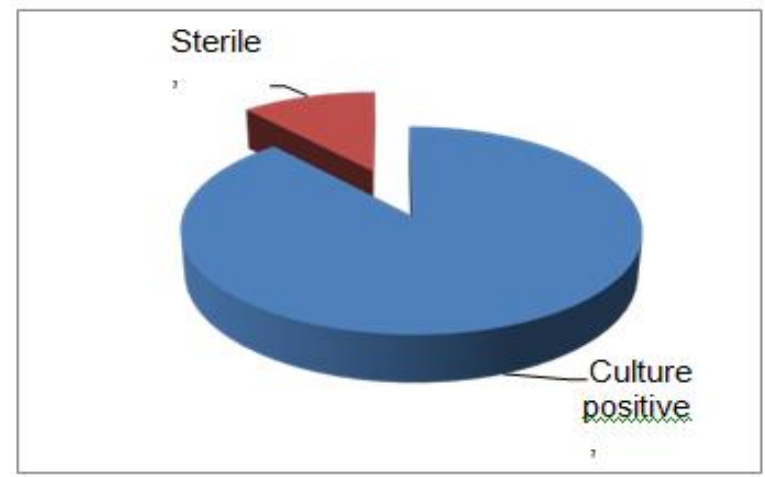

Graph.2 Sex wise distribution of cases of LRTI's

\section{Sex wise distribution}

¿Male $\sqsubset$ Female

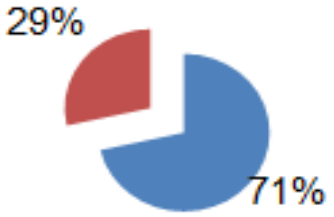

Graph.3 Risk factors associated with LRTI

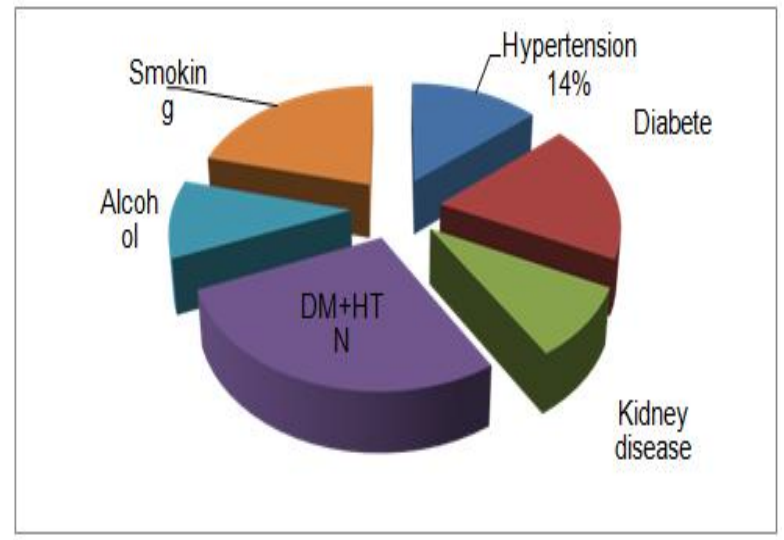

Against GNB, the most active antibiotics were Colistin, Imipenem, Meropenem followed by Amikacin, Gentamycin and Piperacillin/ tazobactam. Carbapenems had been used as the last resort for infections caused by resistant Enterobacteriaceae.
But Carbapenem-Resistant Enterobacteriaceae (CRE) have now been increasingly reported worldwide. $^{21}$ Kanj et al., ${ }^{22}$ pointed that Aminoglycosides, Fluoroquinolones and Cotrimoxazole must be used with caution in serious infections even when they are active in 
vitro. The risk factors associated with LRTI cases were Diabetes, Hypertension, Smoking, Alcohol, Kidney disease and multiple comorbidities. On further analysis of the associated risk factors, it had been found that multipleco-morbidities i.e. patient having more than one risk factor was showing highly prevalent among LRTI cases.

The highest rates of MDR bacteria were found in ICUs and selective pressures from intense antimicrobial exposure contributes to the emergence of MDR bacteria. De-escalation after receiving the culture and sensitivity reports is also not done in many ICUs, thus compounding the problem.

High prevalence of multidrug-resistance were observed in respiratory isolates. For effective management of lower respiratory tract infections, an ultimate and detailed microbiological diagnosis and antibiotic susceptibility testing is required.

In intensive care units and critical care units, antibiotic resistance rates are escalating to the point of complete resistance. With strategies like 'antibiotic cycling' and 'antibiotic stewardship' gaining much importance now, it has become necessary to conserve the already available antibiotics. Hospitals should have an 'antibiotic policy' and facilities for proper monitoring of antibiotic usage along with effective infection control practices to curb the issue of antibiotic resistance worldwide. Moreover, determination of the type of bacterial pathogens and their antibiotic resistance trends aid in better patient management by helping the clinician in the judicious use of antibiotics.

\section{Acknowledgement}

We acknowledge the immense help received from the scholars whose articles are cited and included in references of this manuscript. The authors are also grateful to authors/ editors/ publishers of all those articles, journals and books from where the literature for this article has been reviewed and discussed.

\section{References}

Saha A, Das PK, Das NS, ClinicoBacteriological Profile of Lower Respiratory Tract Infections In Patients Attending Tripura Medical College and dr. Bram teaching hospital, Tripura. Indian journal of applied research. 2018 June; Volume-8 Issue6: page 39-40.

Amutha C, Suganthi M, Katragadda R, LeelaKV, Jayachitra J and Padmanaban Bacterial Profile of Lower Respiratory Tract Infections in Adults and their Antibiotic Susceptibility Pattern with Detection of MRSA, ESBLs and MBLs. International Journal of Current Microbiology and Applied Sciences. 2017; Volume 6 Number 3: page 631639.

Sarmah N, Sarmah A, and Das D K. A Study on the Microbiological Profileof Respiratory Tract Infection (RTI) in Patients Attending Gauhati Medical College \& Hospital. Annals of International Medical and Dental Research. 2016; Volume 2 Issue 5: page 11-15.

Regha, IR, Sulekha, B. Bacteriological profile and antibiotic susceptibility patterns of lower respiratory tract infections in a tertiary care hospital, Central Kerala. International Journal of Medical Microbiology and Tropical Diseases. 2018 October-December; 4(4): 186190.

Dsouza, AO, Rajeswarie, S, Incidence, clinico-microbiological profile in adult patients with lower respiratory tract infections in a tertiary care hospital. Medplus research. 2019 April; Volume 10 Issue 1. 
Elumalai A, Anitha Raj M, Abarna V, Bagyalakshmi R, Reddy S. Studyof Gram Negative Bacterial Isolates From Lower Respiratory Tract Infections (LRTI) and Their Antibiogram Pattern in A Tertiary Care Hospital in South India. Journal of Medical Science And Clinical Research 2016; Volume 04 Issue 11: 14066-14070.

Ratna, S, Devi, KM, Sharma, HS, Yadav, M, Damrolien S and Devi KS. Bacteriological Profile And Antibiotic Susceptibility Pattern Of Lower Respiratory Tract Infection In A Tertiary Hospital In North-East India. 2017 September; Vol. 8, Issue, 9:20337-20340.

Galate LB and Gajbhiye P S. Microbiological Profile and Antibiogram Pattern of Lower Respiratory Tract Infection. International Journal of Humanities, Arts, Medicine and Sciences.2015 April; Volume 3 Issue 4:1-6.

RanaA,\& Mishra AK. Bacteriological Profile Isolated From Lower Respiratory Tract Infections and Their Antibiogram in a Tertiary Care Hospital In Akansha Rana Medical Microbiology. International journal of scientific research. 2015 December; Volume 4 Issue 12: 266-267.

Bajpai T, Bhatambare G, Shrivastava G, Deshmukh A, and Chitnis V. Microbiological profile of lower respiratory tract infections inneurological intensive care unit of a tertiary care center from Central India. Journal of Basic and Clinical Pharmacy. 2013June-August ; Volume4 Issue 3:51-54.

Okesola AO. and Ige O M. Trends in bacterial pathogens of lower respiratory tract infections. The Indian Journal of Chest Diseases \& Allied Sciences. 2008; Volume 50 Issue 3:269-272.

Kalgo M., Nwabuisi C., and Manga S S. Bacterial Pathogens of Lower
Respiratory Tract in University of Ilorin Teaching Hospital, Ilorin, Nigeria. International Journal of Innovative Studies in Sciences and Engineering Technology. 2016 March; Volume 2 Issue 3:1-5.

Preeti S, Pappu K, Nirwan PS, and Meeta S. Bacteriological profile and antibiogram pattern of lower respiratory tract infections in a tertiary care hospital in northern India. International Journal of Pharmaceutical Research and Bio Science. 2013; Voulme 2 Issue 3: 225233.

Amarasinghe N, Athavan M, Jayamanne D, Rajapakshe Y, Sadikeen A, Gunasekara K, Fernando A, Karunanayake L. Bacterial profile and antibiotic susceptibility pattern of adult lower respiratory tract infections in Colombo, Sri Lanka. Journal of Health and Social Sciences. 2018; 3(1): 2736.

Agmy G, Mohamed S, Gad Y, Farghally E, Mohammedin $\mathrm{H}$ and Rashed $\mathrm{H}$. Bacterial Profile, Antibiotic Sensitivity and Resistance of Lower Respiratory Tract Infections in Upper Egypt. Mediterranean Journal of Hematology and Infectious Diseases. 2013; 5(1): 17.

Purti T, Kiran D. Lower Respiratory Tract Infections, Current Etiological Trend and Antibiogram. Pharm Biomed Sci 2014; 04, 03: 249-255.

Thomas AM, Jayaprakash C, and Menon Radhakutty AG. The Patternof Bacterial Pathogens and Their Antibiotic Susceptibility Profile From Lower Respiratory Tract Specimens in a Rural Tertiary Care Centre. Journal of Evolution of Medical and Dental Sciences 2016; 5, 40: 2470-2476.

Panda S, Nandini BP, Ramani T. V. Lower Respiratory Tract Infection- 
Bacteriological Profile and Antibiogram Pattern. International Journal of Current Research andReview.2012; 4,21: 149-155.

Nepal R, Shrestha B, Joshi DM, Joshi R D, Shrestha S, \& Singh A. Antibiotic Susceptibility Pattern of Gramnegative Isolates of Lower Respiratory Tract Infection. Journal of Nepal Health Research Council. 2018; Volume 16(1) Issue 38:22-26.

Tchatchouang S, Nzouankeu A, Kenmoe S, Ngando L, Penlap V, Fonkoua MC, Pefura-Yone EW and NjouomR. Bacterial Aetiologies of Lower Respiratory Tract Infections among Adults in Yaoundé, Cameroon. BioMed Research International. 2019; Volume 19: 1-7

Morrill HJ, Pogue JM, Kaye KS and LaPlante KL. Treatment Options for Carbapenem-Resistant
Enterobacteriaceae Infections. Ofid 2015;1-14.

Kanj S S, and Kanafani Z A. Current concepts in antimicrobial therapy against resistant gram-negative organisms: Extended-spectrum $\quad \beta$-lactamaseproducing enterobacteriaceae, carbapenem-resistant enterobacteriaceae, and multidrug-resistant Pseudomonas aeruginosa. Mayo Clinic Proceedings 2011; 86, 3: 250259.

Standard Operating Procedures (SOP). Surveillance of Priority Bacterial Pathogens under National AMR Surveillance Network, National Programme for Containment of Antimicrobial Resistance. National Centre for disease control, India. February 2019. Internal quality control: page no 7.

\section{How to cite this article:}

Anil A. Gaikwad, Payal Rahangdale, Jyoti A. Iravane (Bajaj), Shaikh Ambreen Fatema Abdul Hafiz and Nashrah Khan. 2021. Microbiological Profile of Lower Respiratory Tract Infections in MICU in a Tertiary Care Hospital. Int.J.Curr.Microbiol.App.Sci. 10(02): 1450-1459. doi: https://doi.org/10.20546/ijcmas.2021.1002.174 